\title{
Olga ran
}

\author{
What Makes Olga Run? \\ Bruce Grierson \\ Henry Holt \& Co., 2014
}

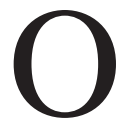

lga Kotelko was one of the most remarkable people around. Sadly, Olga died in June 2014, shortly after this book was published. However, her legacy lives on. She turned 95 in March 2014, and the retired West Vancouver, BC, schoolteacher who took up track and field at 77 held 35 world records for her age group in a variety of running and throwing events. (She bagged nine of those records at a track meet in Budapest, Hungary, in April 2014.) When Vancouver journalist Bruce Grierson met her about 6 years ago, he was immensely curious: "When you're breaking records, rather than hips, at an age most people will never live to see...what gives?" They established a pact: "She would offer herself up to science while I took notes," he writes.

This book takes us along on an entertaining and often laugh-out-loud quest to find out what "gives" with Olga. Along the way, we get to sample from perhaps the most colourful smorgasbord of theories on aging ever cooked up. Grierson accompanies her to medical research facilities and track meets around the globe, interviews the world's authorities on aging, and parses scientific and literary texts to see what factors beyond the "luck of the gene pool" are making Olga "run." Basically, Grierson reasons, if we can understand Olga, we can understand aging.

Grierson writes with verve, and the book quickly nips along as he methodically interrogates all of longevity's

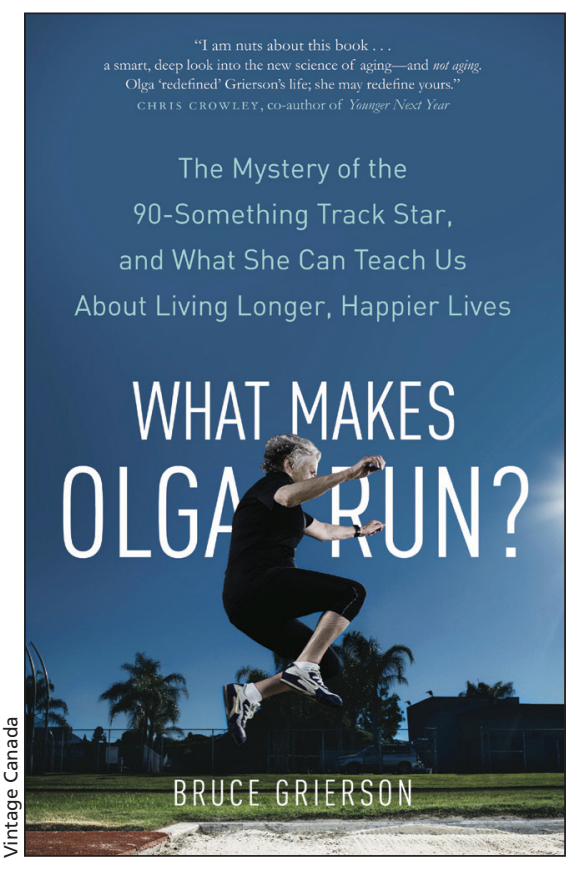

usual suspects: diet, upbringing, genetic code, personality traits. These inquiries lead us into texts on physiology, cognitive science and evolutionary medicine — the territory most doctors need some familiarity with when their patients ask: Why aren't I as healthy as I should be? The answer has good and bad news: the bad news is that despite eons of research into health and longevity, there is no single holy grail; the good news is that there are many of them.

Far from being academic, What Makes Olga Run? digs into aging research in such a refreshing way, and anchors it to such an adorable character, that the book might be the world's first page-turner on geriatric athleticism.

Grierson ranks with American food writer Michael Pollan and, like him, has crafted this book after rigorously field-testing his ideas in the pages of The New York Times Magazine.

Those who like things in neat packages will appreciate the book's concluding nine-point list that summarizes all the lessons the duo learned on their around-the-world quest. These aren't ground-breaking, but with an extraordinary example like Olga, we can't deny the importance of the little things she did to age well, and that we all need to lighten up, manage stress, cultivate a sense of progress and even just be more kind. Demonstrating that kindness doesn't just feel good, but "works," Grierson tips his hat to the evolutionary psychologists who see even in human agreeableness an oft-overlooked key to our survival and longevity: "On the Serengeti, baboons with plenty of good friends thrive. The genes of nice baboons, and nice people, go on."

Any of us seeking to age with as much healthiness as we can muster will learn a lot from this book. Olga's life serves as a mirror: it is a way to examine our own performance. Those reflections can remind us that it is never too late to become reconnected to our bodies. Grierson's final words may not propel you off the couch, but they're certainly food for thought: "Our bodies, from whom we have become estranged, are whispering to us: Let's get back together. So let's."

\section{Alan Cassels BA MPA \\ Faculty of Human and Social Development University of Victoria \\ Victoria, BC}

Editor's note: Alan Cassels has known Bruce Grierson for about 20 years.

CMAJ 2015. DOI:10.1503/cmaj.140600 